\title{
La melancolía elegíaca de finales del XVIII en Francia
}

\section{(The melancholy elegiac in the late $18^{\text {th }}$ century in France)}

\author{
Miguel Ángel García Peinado
}

(Universidad de Córdoba)

Fecha de recepción: 1 de marzo de 2010

Fecha de aceptación: 15 de abril de 2010

Resumen: Trabajo que se ocupa de diseccionar la poesía surgida en Francia ya avanzada la segunda mitad del XVIII, y que en bastantes casos es un precedente de la posterior poesía romántica, sobre todo de Lamartine. El autor de Méditations poétiques copiará temas y situaciones de estos poetas "prerrománticos" franceses, cuyos poemarios desarrollan distintas variedades de la melancolía y sus efectos, desde la "douce mélancolie" de Chamfort a la melancolía del sufrimiento de Millevoye, pasando por las distintas sensibilidades melancólicas de Gilbert, Parny y Legouvé.

Palabras clave: Poesía francesa, Melancolía, Siglo XVIII, Traducción

Abstract: This paper analyzes the poetry arisen well into the second half of the $19^{\text {th }}$ Century in France, which in some cases is a precedent of the subsequent Romantic poetry, especially the poetry written by Lamartine. The author of Méditations poétiques will copy subjects and situations from these French Pre-romantic poets, whose books of poems develop different varieties of the melancholy and its consequences, from the 'douce mélancolie' by Chamfort to the suffering melancholy by Millevoye, going through the different melancholic sensitivities from Gilbert, Parny and Legouvé.

Key words: French poetry, melancholia, XVIIIth, translation

\section{INTRODUCCIÓN}

Melancolía, fatídico estado mental y físico que afecta a los mortales, y que desde que aparece en el ser humano ya se revela como "algo que anula la mente y el cuerpo" y que convierte al sujeto que la sufre, no en el "mal de vivre" anunciado por la canción de una de las musas del existencialismo, Monica Andrée Serf (conocida como "Barbara") ${ }^{1}$, sino más bien en una "imposibilidad de seguir viviendo", un trastorno, desfase o

1 "Ça ne prévient pas quand ça arrive

Ça vient de loin..." 
ataque a la integridad de los sentidos que provoca una verdadera crisis del ser. Inherente a todas las épocas, ha encontrado anclaje ya desde la literatura de la Antigüedad, manifestándose como fenómeno literario en la Edad Media ${ }^{2}$, desarrollándose críticamente en el Renacimiento (sobre todo con Montaigne) y hallado su expresión poética en el XVII en los poemarios de Du Bellay, Théophile de Viau, Saint-Amant, y magistralmente en el XVIII con La Nouvelle Héloïse, verdadero modelo de esa inexpresable "vague à l'âme" ante la contemplación de la naturaleza por parte de Saint-Preux y Julie, personajes que describen, como no se había hecho hasta entonces, la influencia de la naturaleza sobre el alma y las extrañas correspondencias ${ }^{3}$ que unen el paisaje a los sentimientos.

Aunque parece lógico defender la teoría de que en el siglo XVIII la melancolía no echa raíces en Francia (como si ocurrirá en Inglaterra), debido quizás a que ha imperado el erotismo y la retórica (Sade y Bossuet) ${ }^{4}$, y que la obra de Rousseau contendrá en germen todas las efusiones que en el XIX desarrollarán los poetas románticos (con Lamartine a la cabeza), convirtiendo a este estado de tristeza en el motivo principal del poeta en la tierra, así como en una respuesta a la masa ante su exilio social que llega incluso a adquirir lo que podríamos denominar cartas de nobleza terminológicas con apelativos tan reveladores como "mal du siècle", "vague à l'âme" o "vague des passions", "spleen", "néant", ello no es óbice para que ya vayan esbozándose los estados febriles en los que el poeta se siente invadido por lo que Hugo calificará acertadamente en Les Travailleurs de la mer como "le bonheur d'être triste" al referirse a una de las formas en que se manifiesta la melancolía 5 .

\footnotetext{
${ }^{2}$ Los autores medievales reproducen en sus textos el carácter "invasivo" del estado del alma de sus personajes al mostrar como aparecen muy frecuentemente en su corazón experiencias psíquicas muy diversas; son manifestaciones que provienen del delirio, del comienzo del amor, de las crisis amorosas, de la tentación de la nada y de las crisis de identidad, poseyendo todas ellas implicaciones médicas al ser el amor y la amistad "heroicas" las dos grandes enfermedades atrabiliarias identificadas.

${ }^{3}$ No es aún el concepto que en el siglo siguiente desarrollará Baudelaire en su famoso poema de ese mismo título.

${ }^{4}$ Julia Kristeva expone ese punto de vista en una entrevista concedida a Dominique A. Grisoni, a propósito de la publicación de su libro Soleil noir, depression et mélancolie (Paris, Gallimard, 1987): "Les abîmes de l'âme", Magazine littéraire, no 244, juillet-août, 1987, pp. 16-18.

${ }_{5}^{5}$ Aclaremos que el término puede englobar tres aspectos o significaciones ligadas a la palabra: a) por una parte, el aspecto psiquiátrico: afección grave que se manifiesta por una ralentización psíquica que conduce a la extinción del gusto por la vida, por el deseo y por la palabra, así como a la paralización de todo tipo de actividad y guía al que la padece a la atracción irresistible por el suicidio

b) una forma más ligera de este abatimiento que alterna con estados de excitación, forma dependiente de estados neuróticos denominados depresión
} 
En el siglo XVIII en Francia, médicos y novelistas analizan minuciosamente los determinismos que explican esta tristeza. Lógicamente donde primero se paran es en el temperamento, terreno sentimental que predispone a la melancolía, aunque no son menos importantes la edad, el sexo y el clima; por lo que respecta a la primera, la más vulnerable es la adolescencia, en cuanto a las segunda variable, las mujeres son más propicias a caer en ese estado ${ }^{6}$; en lo tocante a la tercera, el clima, se conviene en afirmar que Francia no es lugar que sea más propicio que otros países, como sí ocurre con Inglaterra, tierra de brumas y climas húmedos que no concuerdan bien con la salud mental. Nada extraño esto último, si pensamos que ya un clásico inglés en los estudios sobre la melancolía afirmaba que "Así como es el aire, así son los habitantes de ese país" ${ }^{\prime 7}$. En Inglaterra, en la época tratada, las mujeres padecían de "spleen", término que entra en la literatura francesa en 1753 , con el poeta Feutry ${ }^{8}$ que la cita en su poema "Le temple de la mort"; el autor alude a la etimología del término y añade que los ingleses lo utilizan para designar una afección vaporosa, una tristeza interior. Y está en lo cierto si pensamos que Lady Mary Wortley Montagu (1689-1762), la escritora, feminista temprana, aristócrata y persona muy conocida en la alta sociedad inglesa, así como famosa por haber introducido la inoculación contra la viruela, examina el concepto en un poema titulado A RECEIPT TO CURE THE VAPOURS:

I

Why will Delia thus retire,

And idly languish life away?

While the sighing crowd admire,

'Tis too soon for hartshorn tea:

c) un tercer aspecto, más común, caracterizado por una opinión difusa que lleva al que la sufre a una "vague à l'âme", a un "spleen" (palabra inglesa que no significa otra cosa que bazo), una nostalgia cuyos ecos se plasman en el arte y en la literatura

${ }^{6}$ Por lo que concierne a los remedios tradicionales para combatir la melancolía la amistad figura entre los primeros; médicos y enciclopedistas lo subrayan, así el médico francés de probable origen escocés Bernard de Gordon (h.1260-1318) en su obra Practica dicta Lilium medicine (1305), como luego Robert Burton, del mismo modo que los escritores de la Edad Media. El relato de Claris y Laris se puede citar como ejemplo de lo afirmado

${ }^{7}$ Me refiero al ya citado Robert Burton y su famosa obra, cuyo título completo es: The Anatomy of Melancholy, What it is: With all the Kinds, Causes, Symptomes, Prognostickes, and Several Cures of it. In Three Maine Partitions with their several Sections, Members, and Subsections. Philosophically, Medicinally, Historically, Opened and Cut Up. Publicada en 1621, reeditada en 1624, 1628, 1632, 1638, 1651, 1660 y 1676; la versión de referencia es la de Jackson Holbrook, de 1932 (London, Dent). Los tres volúmenes de la Clarendon Press/Oxford University Press edition (1989-94) no se encuentran fácilmente; tienen una Introduction de $\mathrm{J}$. B.Bamborough y fue editada por Thomas C. Faulkner, Nicolas K. Kiessling y Rhonda L. Blair.

${ }^{8}$ Cf. García Peinado, M. Á: "La influencia en Francia de la poesía sepulcral inglesa del XVIII: Les Tombeaux (Aimé Feutry), Les Tombeaux champêtres (Chateaubriand), Les Sépultures (Lamartine), Hermeneus, ํo 7, 2005. 
II

All those dismal looks and fretting

Cannot Damon's life restore;

Long ago the worms have eat him, You can never see him more.

III

Once again consult your toilette,

In the glass your face review:

So much weeping soon will spoil it,

And no spring your charms renew.

IV

I, like you, was born a woman,

Well I know what vapors mean:

The disease, alas! is common;

Single, we have all the spleen.

$\mathrm{V}$

All the morals that they tell us,

Never cured the sorrow yet:

Chuse, among the pretty fellows,

One of honor, youth, and wit.

VI

Prithee hear him every morning

At least an hour or two;

Once again at night returning-

I believe the dose will do. ${ }^{9}$

${ }^{9}$ En este texto, como en todos los siguientes, he respetado la grafía original; veamos su traducción al español:

UN REMEDIO PARA CURAR LOS VAPORES

I

¿Por qué se abandona de este modo Delia

y ociosamente deja languidecer su vida?

Mientras la multitud con estupor se asombra,

es demasiado pronto para un te de amoníaco.

II

Todas esas miradas sombrías y preocupadas

no pueden devolverle ya la vida a Damón;

tiempo ha que los gusanos entero lo engulleron,

nunca más lograrás poder volverlo a ver.

III

Recupera de nuevo tu acicalamiento,

examina tu cara delante del espejo:

un llanto tan copioso pronto la estropeará

y primavera alguna sanará tus encantos.

IV

Yo, lo mismo que tú, he nacido mujer

bien conozco el alcance de todos los vapores:

la afección, ipor desgracia!, es algo muy común

y sencillo, pues todas melancolía sufrimos.

Hikma 9 (2010), 55-86 
No es tampoco raro que aparezcan en Francia obras alusivas a la afección, basadas en los vapores; así, en 1758, publica el físico Joseph Raulin (1708-1784) su Traité des affection vaporeuses du sexe $e^{10}$, en la que en su "Discours préliminaire" el autor, basándose en su amplia experiencia clínica, anuncia claramente de que va a ocuparse:

Les vapeurs affligeoient la plus belle partie de l'humanité dès la naissance de la Médecine; elles étoient déja fréquentes du temps de Démocrite \& d'Hippocrate; elles l'étoient encore plus du temps de Galien. Ces Auteurs déploroient le sort des femmes par rapport au nombre de maladies auxquelles elles étoient exposées. Depuis ces temps éloignés, ces maladies se sont multipliées, sont devenues plus dangereuses, plus compliquées, plus épineuses \& plus difficiles à guérir; les affections vaporeuses en sont, entr'autres, un exemple trop frappant: c'est en faisant attention à leurs différens symptômes que les Médecins modernes ont observé que les maladies des femmes excedent de plus de deux cents celles qui sont particulieres aux hommes.

II y a déjà plus d'un siècle que les vapeurs sont endémiques dans les grandes Villes; la plupart des femmes qui jouissent des commodités de la vie, sont vaporeuses; on peut dire qu'elles achètent par une fuite de langueurs l'agrément des richesses.

On m'a engagé à rechercher la cause de ces désordres, les moyens d'y remédier \& de les prévenir. Cette attention étoit d'autant plus nécessaire, qu'on s'apperçoit tous les jours que les vapeurs deviennent héréditaires, qu'elles sont très-souvent compliquées avec d'autres maladies, \& qu'elles les rendent plus dangereuses \& plus

\section{$\checkmark$}

Cualquier tipo de fórmula que alguien nos recomienda nunca hasta ahora ha logrado curarnos la tristeza:

elige entre los hombres hermosos de tu entorno uno que posea humor, juventud e ingenio.

VI

Te sugiero que lo oigas cada mañana hablarte al menos una hora, y si pueden ser dos,

y obres del mismo modo cuando cae la noche; creo que con esta dosis ya será suficiente.

${ }^{10}$ El título completo de la segunda edición es: Traité des affections vaporeuses du sexe Avec l'exposition de leurs Symptômes, de leurs différentes Causes, \& la méthode de les guérir. (On y trouve aussi des connoissances relatives aux Affections vaporeuses des Hommes). Par M. Joseph Raulin, Docteur en Médecine, Conseiller-Médecin ordinaire du Roi, des Académies Royales des Belles-Lettres, Sciences \& Arts de Bordeaux \& de Rouen. Seconde Edition, revue par l'Auteur. Paris, Chez Jean-Thomas Hérissant, 1859.

Hikma 9 (2010), 55-86 
rebelles. Je ne manque pas de zèle pour m'acquitter de ce devoir de mon état; je profite pour le remplir des observations que j'ai faites pendant plusieurs années dans le cours d'une pratique exacte \& laborieuse: j'évite avec soin les systèmes hasardés qui ont séduit les Médecins durant un nombre de siècles, \& qui les ont empêché d'appercevoir la véritable cause des vapeurs. ${ }^{11}$

En su "Avertissement à la seconde édition", Raulin precisa aún más, disertando ya sobre el término melancolía:

L'ACCUEIL favorable que le Public a bien voulu faire à mon Livre des Affections vaporeuses, m'a engagé à faire, pour cette seconde Edition, plusieurs observations utiles. Je me fuis étendu principalement sur l'éthiologie \& sur la cure de la mélancolie des hommes. On étoit surpris de ce que j'en avois parlé plus succinctement que des vapeurs des femmes; on m'en a fait des reproches, mais je ne pouvois que remplir l'objet qu'on m'avoit proposé d'abord, en me confiant te soin de traiter cette matière. D'ailleurs, j'observe dans mon Livre, que les causes des vapeurs sont les mêmes dans les deux Sexes, si l'on en excepte celles qui proviennent de quelques maladies particulières aux femmes. Les Connoisseurs dans l'art de guérir sont toujours la différence de ces causes: ce n'est qu'à eux seuls qu'on peut en confier la cure. Je ferai tous mes efforts pour perfectionner cet Ouvrage par une fuite d'Observations; je le dois au Public en reconnoissance du bon accueil qu'il lui a fait. $^{12}$

En la misma vía de la obra de Raulin sigue el médico de la Facultad de Medicina de Montpellier (lugar donde también ejercía el ya citado Bernad de Gordon) ${ }^{13}$ Pierre Pomme, al publicar en 1765 su Traité des affections vaporeuses des deux sexes. El médico da un paso más en el tratamiento de la melancolía al localizarla en el sistema nervioso:

QUARANTE ans se sont écoulés depuis la publication de mon Traité des Affections Vaporeuses des deux Sexes. J'ai prouvé et démontré dans cet ouvrage, qui a déjà produit six éditions, sans compter les contrefaçons, et qui a été traduit en plusieurs langues étrangères, que la tension des nerfs étoit la véritable cause de ces maladies, maladies le plus souvent incurables et mortelles, avant ma découverte, parce

\footnotetext{
${ }^{11}$ Ob. cit., pp. vii-ix.

12 Ibidem, pp. xliii-xliv.

${ }^{13}$ No olvidemos que la Facultad de Medicina Montpellier era una de las más reputadas de Europa, donde va a estudiar Rabelais en 1530 y donde impartía docencia el famoso médico y naturalista Guillaume Rondelet (1507-1566), célebre por sus trabajos sobre los peces.
} 
qu'on en attribuoit la cause au relâchement ou à la foiblesse des nerfs, et que l'on se conduisoit dans leur traitement en conséquence de cette erreur $^{14}$.

La clarividencia del autor se pone de relieve al explicar cómo los hombres son melancólicos o hipocondríacos, mientras que las mujeres "vaporeuses" o histéricas, siendo causa de esta afección en ellas el útero. Los "vapeurs" remiten a un imaginario sexual y, en este camino, Joseph Bressy menciona todas sus consecuencias: convulsiones, dolores de cabeza o vértigo, síncopes, estreñimiento, problemas respiratorios, suspiros y llantos, ventosidades y eructos, sensación de agobio, etc. ${ }^{15}$

Aplicados a la ficción literaria la melancolía es una especie de losa que confluye en Francia en las últimas décadas del siglo XVIII, y cuyos efectos en poesía responden a las inquietudes de la Julie de Rousseau, en la que se mezclan la frustración sexual y el impulso religioso (posiblemente refugio o consecuencia de lo anterior); se trata, de un modo general, en plasmar y confesar los sentimientos complaciéndose en el propio dolor que estos producen.

\section{DOS PREDECESORES DE LAMARTINE: THOMAS Y LÉONARD}

Unas décadas antes de que Lamartine exprese su dolor por la no comparecencia de Elvire (Julie Charles) a su cita con él, dos poetas del siglo anterior confiesan las mismas inquietudes, a veces con una similitud asombrosa, en la plasmación de lo que podríamos denominar melancolía prerromántica; se trata de Antoine Léonard Thomas ${ }^{16}$ y Nicolas Germain Léonard ${ }^{17}$. Veamos los poemas en los que debió basarse Lamartine para su "Lac":

\footnotetext{
${ }^{14} 6^{\mathrm{e}}$ édition, Tome II, p.174.

${ }^{15}$ Joseph Bressy, Recherches sur les vapeurs, Paris-London, Planche, 1789.

${ }^{16}$ Antoine Léonard Thomas (1732-1785), originario de Clermont-Ferrand, es famoso por los reiterados elogios que escribió sobre personajes célebres de su tiempo, obteniendo en cinco ocasiones el premio de elocuencia en la "Académie" (1759, 1760, 1761, 1763, 1765), siendo también laureado con el premio de poesía en 1762. Debuta en la literatura en 1756 con Réflexions philosophiques et littéraires sur le poème de "la Religion naturelle", en el que atacaba a Voltaire 1762. No obstante, fue amigo de los filósofos y asiduo asistente a los salones de Mme Geoffrin (que le pasó una pensión y le legó una renta vitalicia de 1275 francos), de Mlle de Lespinasse y de Mme Necker. Fue, asimismo, profesor y miembro de la "Académie de Lyon". Entró en la Academia en 1766, y en 1773 publicó su teoría Essai sur les éloges.

${ }^{17}$ Nicolas Germain Léonard (1744-1793) fue buena parte de su vida un exilado; nacido en la isla Guadalupe, viaja luego a Francia y a Lieja para funciones oficiales. De vuelta a su patria es mal visto por sus compatriotas a causa de su trabajo jurídico; morirá en Nantes, esperando un barco que lo lleve de nuevo a su isla. Poeta célebre por sus Idylles, imitados de los del suizo de expresión alemana Salomon Gessner, es un escritor de sensibilidad melancólica, siendo un
} 
ODE SUR LE TEMPS ${ }^{18}$

Le compas d'Uranie a mesuré l'espace.

Ô Temps, être inconnu que l'âme seule embrasse,

Invisible torrent des siècles et des jours,

Tandis que ton pouvoir m'entraîne dans la tombe,

J'ose, avant que j'y tombe,

M'arrêter un moment pour contempler ton cours.

Qui me dévoilera l'instant qui t'a vu naître?

Quel œil peut remonter aux sources de ton être?

Sans doute ton berceau touche à l'éternité.

Quand rien n'était encore, enseveli dans l'ombre

De cet abîme sombre,

Ton germe y reposait, mais sans activité...

Ô Temps, suspends ton vol, respecte ma jeunesse;

Que ma mère, longtemps témoin de ma tendresse,

Reçoive mes tributs de respect et d'amour;

Et vous, Gloire, Vertu, déesses immortelles,

Que vos brillantes ailes

Sur mes cheveux blanchis se reposent un jour.

ODA SOBRE EL TIEMPO

El cartabón de Urania ha medido el espacio ¡Oh tiempo, ser ignoto que sólo el alma abraza, Invisible torrente de los siglos y días,

mientras que tu poder a la tumba me arrastra oso, antes de allí caer,

pararme un instante para así ver tu curso.

¿Quién me desvelará la hora en que naciste?

¿Qué iris subirán a la raíz de tu ser?

Tu cuna, es seguro, que a la eternidad toca.

Cuando no existía nada envuelto en la sombra

de este sombrío abismo,

tu germen allí estaba, aunque estuviera inane..

adelantado del Romanticismo francés por la introducción de topoi y temas de los que se apropiarán los románticos.

${ }^{18}$ El poema completo está traducido por la profesora Díaz Alarcón en el número 2 de la Revista Cuadernos Andaluces de Traducción Literaria, de la Consejería de Cultura de la Junta de Andalucía, ISSN 2171-3995, que aparecerá a comienzos de 2011, y del que transcribimos sólo las dos primeras estrofas y la última.

Hikma 9 (2010), 55-86 
Tiempo, suspende el vuelo, mi juventud respeta;

que mi madre, testigo siempre de mi ternura,

mis tributos reciba y de respeto y de amor

$y$ vos Gloria, Virtud, oh diosas inmortales,

que vuestras áureas alas

en mi cano cabello descansen algún día.

Hikma 9 (2010), 55-86 


\section{L'ABSENCE}

Des hameaux éloignés retiennent ma compagne.

Hélas! Dans ces forêts qui peut se plaire encor?

Flore même à présent déserte la campagne

Et loin de nos bergers l'amour a pris l'essor.

Doris vers ce coteau précipitait sa fuite,

Lorsque de ses attraits je me suis séparé:

Doux zéphyr! si tu sors du séjour qu'elle habite,

Viens! que je sente au moins l'air qu'elle a respiré.

Quel arbre, en ce moment, lui prête son ombrage?

Quel gazon s'embellit sous ses pieds caressants?

Quelle onde fortunée a reçu son image?

Quel bois mélodieux répète ses accents?

Que ne suis-je la fleur qui lui sert de parure,

Ou le nœud de ruban qui lui presse le sein,

Ou sa robe légère, ou sa molle chaussure,

Ou l'oiseau qu'elle baise et nourrit de sa main!

Rossignols, qui volez où l'amour vous appelle,

Que vous êtes heureux! que vos destins sont doux!

Que bientôt ma Doris me verrait auprès d'elle

Si j'avais le bonheur de voler comme vous!

Ah! Doris, que me font ces tapis de verdure

Ces gazons émaillés qui m'ont vu dans tes bras,

Ce printemps, ce beau ciel, et toute la nature,

Et tous les lieux enfin où je ne te vois pas?

Mais toi, parmi les jeux et les bruyantes fêtes, $\mathrm{Ne}$ va point oublier les plaisirs du hameau, Les champêtres festons dont nous parions nos têtes, Nos couplets ingénus, nos danses sous l'ormeau!

Ô ma chère Doris, que nos feux soient durables! II me faudrait mourir, si je perdais ta foi.

Ton séjour t'offrira des bergers plus aimables,

Mais tu n'en verras point de plus tendres que moi.

Que ton amant t'occupe au lever de l'aurore,

Et quand le jour t'éclaire, et quand il va finir;

Dans tes songes légers, qu'il se retrace encore,

Et qu'il soit, au réveil, ton premier souvenir.

Si mes jaloux rivaux te parlaient de leur flamme, 
Rappelle à ton esprit mes timides aveux:

Je rougis, je tremblai; tu vis toute mon âme

Respirer sur ma bouche et passer dans mes yeux.

Et maintenant, grands dieux! quelle est mon infortune!

De mes plus chers amis je méconnais la voix,

Tout ce qui me charmait m'afflige et m'importune;

Je demande Doris à tout ce que je vois.

Tu reposais ici; souvent dans ce bocage,

Penché sur tes genoux, je chantais mon amour:

Là, nos agneaux paissaient au même pâturage;

Ici, nous nous quittions vers le déclin du jour.

Revenez, revenez, heures délicieuses,

Où Doris habitait ces tranquilles déserts,

L'écho répétera mes chansons amoureuses,

Et sur ma flûte encor je veux former des airs.

LA AUSENCIA

Aldeas alejadas retienen a mi amada.

¡Ay! En estos bosques, ¿quién puede aún complacerse?

Ahora hasta Flora huye de la campiña

y lejos de pastores emprende el amor vuelo.

Doris a esta ladera su huida precipitaba cuando de sus encantos yo me he alejado: si sales, idulce céfiro!, de la mansión que habita iven!, que yo huela al menos el aire que respira.

¿En este instante, qué árbol le presta a ella su sombra? ¿Qué hierba se embellece bajo sus pies mimosos? ¿Qué ola afortunada ha grabado su imagen? ¿Qué bosque melodioso repite sus sonidos?

¡No soy la flor, yo acaso, que le sirve de adorno, o el nudo de la cinta que presiona sus senos, o su ropa ligera, o su fino calzado, o el pájaro que besa y alimenta en su mano!

¡Jilgueros que voláis donde el amor os llama, cuán felices que sois!, ;cuán dulce es vuestro sino! ¡Muy pronto ya mi Doris me vería cerca de ella si tuviera la dicha de volar cual vosotros!

¡Ah! Doris, ¿qué me causan estas alfombras verdes, esta hierba esmaltada que me ha visto en tus brazos, 
la hermosa primavera, el cielo y la natura, y todos los lugares en los que no te veo?

¡Pero tú, entre los juegos y las ruidosas fiestas, no logras olvidar los placeres de aldea, las guirnaldas campestres que ornaban nuestras frentes, nuestros versos ingenuos, bailes bajo los olmos!

¡Oh, querida Doris, que nuestro amor perdure! debería morirme si en ti la fe perdiera. te ofrecerá tu estancia pastores más amables. mas no verás ninguno que sea que yo más tierno.

Que tu amante te atienda al despuntar la aurora, y cuando el día te alumbre, cuando vaya a acabar; en tus sueños ligeros que aún recordar se haga, y que sea, al despertar, tu recuerdo primero.

Si mis celosos émulos de su pasión te hablaran, recuérdale a tu espíritu mis confesiones tímidas: enrojecí, temblé; tú viste toda mi alma respirar en mi boca y plasmarse en mis ojos.

¡Y ahora, grandes dioses!, ¿cuál es mi infortunio! De mis más caros íntimos desconozco la voz, todo lo que gustábame me aflige e importuna; veo la imagen de Doris en todo lo que miro.

Reposabas en esta floresta, con frecuencia, vencido en tus rodillas, yo cantaba mi amor: allí, nuestros corderos pacían en igual dehesa; aquí nos despedíamos al ocultarse el día.

Volved, volved de nuevo, momentos deliciosos, en que habitaba Doris en estos quietos páramos, mis canciones el eco repetirá, amorosas, y aún sobre mi flauta quiero moldear canciones. 


\section{VARIEDADES DE LA MELANCOLÍA}

Dado que estamos diseccionando a autores que escriben en un período denominado prerromántico, aclaremos, tanto por lo que concierne a la aparición de la temática romántica como del epíteto "romantique" en Francia, que el rastro del término se sigue desde la publicación en 1777 del tratado de René-Louis de Girardin De la composition des paisages, siendo éste el primer autor que rechaza la traducción de la palabra inglesa romantic por "romanesque" (se la había traducido mucho antes por "pittoresque"), definiendo de este modo la situación "romantique" en el marco del paisaje:

Sans être farouche ni sauvage, la situation romantique doit être tranquille et solitaire afin que l'âme n'y éprouve aucune distraction et puisse s'y livrer tout entière à la douceur d'un sentiment profond.

Así pues, debe ser en un cierto contexto paisajístico como deberemos entender la poesía de los autores que veremos, y también la de otros como Chênedollé y Fontanes ${ }^{19}$, en la encrucijada del siglo XVIII. Así, el paisaje puede ser cambiante y conducir directamente a las tumbas y otros lugares pavorosos. ${ }^{20}$ En este contexto de comunión con el paisaje y la naturaleza, único consuelo para el escritor en su meditación interior causada por el desengaño del mundo, algunos poetas expresan su melancolía a la manera "prerromántica", anticipándose al poeta de Mâcon, y en la segunda mitad del XVIII cultivan la melancolía en sus poemas atendiendo a una

\footnotetext{
${ }^{19}$ Sirvan como ejemplo de lo que decimos estos versos de la composición "Poème sur la nature et sur l'homme" (1777):

Ô Temps! Dont le vol fuit et sans fin recommence,

Ô Temps! fais des saisons tourner la roue immense,

Que les ans sur les ans reviennent s'entasser:

La Nature en travail ne saurait se lasser...

O estos otros de "Le jour des morts dans une campagne":

L'invisible union de la terre et des cieux,

Tout enflamme, agrandit, émeut l'homme sensible ;

Il croit avoir franchi ce monde inaccessible..

(Citados en: Anthologie de la poésie française $X V I I I^{e}$ siècle, $X I X^{e}$ siècle, $X X^{e}$ siècle, textes choisis, présentés et annotés par Martine Bercot, Michel Collot et Catriona Seth, Paris, Gallimard, 2000, pp. 364-365.

${ }^{20}$ Será Aymé Feutry el primero que en sus poemas adopte un tono decididamente macabro con su poema "Les Tombeaux", en 1755, bastantes años antes de las traducciones de Le Tourneur de los poetas ingleses de la denominada "Graveyard School".
} 
heterogeneidad que les viene dada por sus características personales; se trata de una mezcla de influencia inglesa de todo lo gótico, de lo que algunos críticos denominarán "ruinisme", de la propia complacencia en el retiro solitario y de todos los topoi o lugares comunes del hombre sensible en la literatura occidental que se repiten una y otra vez, conformando una situación propicia al hombre solitario en la que pueda entregarse por completo a profundas meditaciones, alusivas a su condición de ser humano desgraciado, incomprendido y en total desacuerdo con la sociedad. En efecto, casi todos en un momento $u$ otro de su vida, y debidos a desengaños amorosos o simplemente por ese desarraigo en la época y sociedad que les ha tocado vivir, intentan suicidarse: bien en el pleno sentido del término (Chamfort) bien desoyendo los consejos de los médicos que tratan de preservar su precaria salud (Millevoye).

Como consecuencia de ese malestar todos ellos, por medio de sus escritos, reivindican una libertad e independencia que los lleva a chocar frontalmente con los poderes constituidos; posiblemente, esa necesidad de sentirse libre sea la que provoca la expresión de una poesía melancólica, refugio interior en el cual el poeta da rienda suelta a sus anhelos, prefigurando ya la vena romántica de Lamartine y el desencanto posterior del romanticismo. Representantes de estos poetas, entre otros, son los que mencionamos a continuación, junto con uno de sus poemas más representativos, plasmación cada uno de ellos de un tipo específico de melancolía.

\subsection{Chamfort y la "douce mélancolie",21}

${ }^{21}$ Nicolas de Chamfort (1740-1794) era el pseudónimo de Sébastien-Roch Nicolas, cuya vida estuvo marcada por la paradoja de triunfar, al tiempo que quería escapar de las sujeciones sociales; en literatura se debatirá entre un "rousseauismo" nostálgico y la sátira aristocrática. Su obra más conocida: Maximes, pensées, caractères et anecdotes aparecen en 1795, gracias a los desvelos del poeta Ginguené. Una tentativa de suicidio, mal curada, en 1793 lo llevará a la tumba con un final patético debido a la lucidez de sus últimos momentos: "ma vie entière est un tissu de contrastes avec mes principes". Es comprensible que una figura tan contradictoria atrajera a Albert Camus, que le dedica unas páginas en sus ensayos poniendo de manifiesto sus contradicciones, pero reconociendo sus méritos: “...Chamfort cependant me paraît un des plus enseignants parmi nos moralistes. Mais je le dis tout de suite, c'est qu'en portant ces jugements dans le général, il est infidèle au principe le plus secret de son art. En toute autre occasion, il procède d'une manière bien différente qui fait son originalité et sa profondeur" ("Introduction aux Maximes de Chamfort", en Essais critiques, Essais, Paris, Gallimard, 1965, pp. 1099-1109).

Añado que en el apartado de máximas y reflexiones, encontramos algunas espléndidas de profundidad y realismo, como este pensamiento sobre las mujeres: "La mujer es como la sombra: si le huyes, sigue; si la sigues huye". Por último, a título anecdótico, digamos que en el tomo primero de las CEuvres complètes de Chamfort (Paris, Maradan, MDCCXII), tras el epígrafe "Poésies diverses" podemos encontrar el poema titulado "Les Fêtes espagnoles", compuesto en 1792 (pp. 387-398), cuyos primeros versos son éstos: 
L'HEUREUX TEMPS ${ }^{22}$

Temps heureux où régnaient Louis et Pompadour! Temps heureux où chacun ne s'occupait en France Que de vers, de romans, de musique, de danse, Des prestiges des arts, des douceurs de l'amour! Le seul soin qu'on connût était celui de plaire;

On dormait deux la nuit, on riait tout le jour; Varier ses plaisirs était l'unique affaire.

A midi, dès qu'on s'éveillait,

Pour nouvelle on se demandait

Quel enfant de Thalie, ou bien de Melpomène,

D'un chef-d'œuvre nouveau devait orner la scène; Quel tableau paraîtrait cette année au Salon;

Quel marbre s'animait sous l'art de Bouchardon;

Ou quelle fille de Cythère,

Astre encore inconnu, levé sur l'horizon,

Commençait du plaisir l'attrayante carrière.

On courait applaudir Dumesnil ou Clairon,

Profiter des leçons que nous donnait Voltaire,

"II me souvient d'avoir passé deux mois

Dans un château de gothique structure,

Flanqué de tours, imposante masure

Dont le seigneur m'ennuyait quelquefois-,

Ou me grondoit quand je daignois l'entendre,

Mais, curieux, il me plaisoit d'apprendre

Mainte anecdote; il avoit vu des rois,

Des empereurs, des princes d'Allemagne:

Ces cours vraiment ont de très-bons endroits.

Sa favorite étoit la cour d'Espagne;

Il la citoit sans relâche et partout,

Cherchant quelqu'un qui pour elle eût du goût.

Du roi Philippe et de la Parmesane

J'ai remporté des traits assez plaisans,

Je dis, pour moi; plaisans pour un profane

Qui veut, de loin, des princes amusans.

Mon rabâcheur trouvoit son passe-temps

A parler d'eux, de lui, de leurs caresses.

Il possédoit des reines, des princesses,

En bague, en boîte, en bijoux bien montés;

Rois, électeurs, en ordre étiquetés;

Ayant garni tout un écrin d'altesses,

Près de la tombe, épris des dignités,

Et raffolant surtout des majestés..."

${ }^{22}$ El poema está incluido en: CEuvres de Chamfort, précédées d'une étude sur sa vie et sur son esprit par Arsène Houssaye, Paris, Adolphe Delahays, 1857, pp. 234-235.

Hikma 9 (2010), 55-86 
Voir peindre la nature à grands traits par Buffon.

Du profond Diderot l'éloquence hardie

Traçait le vaste plan de l'Encyclopédie;

Montesquieu nous donnait l'esprit de chaque loi;

Nos savants, mesurant la terre et les planètes,

Éclairant, calculant le retour des comètes,

Des peuples ignorants calmaient le vain effroi.

La renommée alors annonçait nos conquêtes;

Les dames couronnaient, au milieu de nos fêtes,

Les vainqueurs de Lawfeld et ceux de Fontenoy.

Sur le vaisseau public, les passagers tranquilles

Coulaient leurs jours gaiement dans un heureux repos.

Et, sans se tourmenter de soucis inutiles,

Sans interroger l'air, et les vents, et les flots.

Sans vouloir diriger la flotte,

Ils laissaient la manœuvre aux mains des matelots,

Et le gouvernail au pilote.

\section{EL TIEMPO FELIZ}

¡Feliz tiempo el del reino de Louis y Pompadour!

¡Feliz tiempo en que todos se entregaban en Francia

a los versos, novelas, la música y la danza,

al prestigio del arte y de amor las dulzuras!

la única diligencia era la de agradar;

se dormía en par de noche, se reía durante el día; alterar los placeres era el único asunto.

Al despertarse, al mediodía,

se requerían las novedades,

qué hijo de Talía, o que hijo de Melpómene,

con nueva obra maestra debía adornar la escena;

qué cuadro colgarían ese año en el Salón;

qué mármol cobraría vida por Bouchardon ${ }^{23}$;

o qué hija de Citerea,

astro aún desconocido, que sobre el horizonte,

del placer comenzaba la atrayente carrera.

Se corría a aplaudir a Dumesnif ${ }^{24}$ o Clairon $^{25}$,

a aplicar las lecciones que nos daba Voltaire,

ver pintar la natura por Buffon con gran trazo.

Del hondo Diderot la elocuencia atrevida

trazaba el vasto plan de la Enciclopedia;

\footnotetext{
${ }^{23}$ Edmé Bouchardon (1698-1762), escultor considerado el mejor de su generación. Autor de la fuente de la "Rue de Grenelle".

${ }^{24}$ Marie Françoise Marchand (1711-1803), conocida como Mlle Dumesnil, actriz que sobresalió interpretando las tragedias de Racine.

${ }^{25}$ Claire Joseph Hippolyte Léris (1723-1803), Ilamada Mlle Clairon; era hija natural de un sargento del ejército, y llegó a ser una actriz famosa interpretando sobre todo a Voltaire.
} 
nos daba Montesquieu de cada ley el espíritu;

nuestros sabios midiendo la tierra y los planetas,

explicar, calculando la vuelta de cometas,

de los pueblos incultos calmar el pavor vano.

El renombre anunciaba todas nuestras conquistas;

las damas laureaban en medio de las fiestas,

a invictos de Lawfeld ${ }^{26}$ y a los de Fontenoy.

Sobre la nave pública, los tranquilos viajeros

pasaban días alegres en un feliz reposo.

$Y$, sin atormentarse con recelos inútiles,

sin preguntarle al aire, los vientos y a las olas.

Sin querer dirigir la flota,

dejaban la maniobra en manos marineras,

y el timón al piloto.

${ }^{26}$ Referencia a la batalla Lauffeld (ortografiada también Lawfeld o Lafelt) al oeste de Maastricht el 2 de julio de 1747, con motivo de la invasión francesa de los Países bajos austríacos. 


\title{
2.2. Gilbert y la melancolía sensiblera ${ }^{27}$
}

\author{
Le Poete malheureux ${ }^{28}$ \\ Vous que l'on vit toujours chéris de la fortune, \\ De succès en succès promener vos désirs, \\ Un moment, vains mortels, suspendez vos plaisirs:
}

${ }^{27}$ Nicolas-Joseph Laurent (1750-1780) representa el prototipo de poeta infortunado; según él,
el curso de sus males remontaba a su nacimiento. Su muerte prematura de una caída del
caballo (no de hambre como indica su leyenda) le valió encarnar la figura de poeta maldito, el
"Chatterton" francés citado por Vigny en su Stello. La implacable enemistad de La Harpe le hizo
verter este juicio sobre Gilbert:

"C'est ce petit rimeur de tant de prix enflé;

Qui, sifflé pour ses vers, pour sa prose sifflé,

out froissé des faux pas de sa muse tragique,

Tomba de chute en chute au trône académique".

Opinión injusta sobre un hombre que había escrito estas admirables "stances":

"Au banquet de la vie, infortuné convive,

J'apparus un jour et je meurs:

Je meurs, et sur la tombe où lentement j'arrive,

Nul ne viendra verser des pleurs.

Salut, champs que j'aimais, et vous, douce verdure,

Et vous, riant exil des bois!

Ciel, pavillon de l'homme, admirable nature,

Salut pour la dernière fois!

Ah! puissent voir longtemps votre beauté sacrée

Tant d'amis sourds à mes adieux!

Qu'ils meurent pleins de jours, que leur mort soit pleurée!

Qu'un ami leur ferme les yeux!'

(Al festín de la vida, comensal desdichado, aparecí un día y muero:

muero, y sobre la tumba a la que lento llego, nadie vendrá por mí a derramar una lágrima.

¡Adiós, campos que amaba, y vos, dulce verdor, y vos, risueño exilio, de los bosques!

¡Cielo, emblema del hombre, admirable natura, adiós ya por vez última!

¡Podrán ver largo tiempo vuestra sacra belleza tantos amigos sordos a mis adioses!

¡Qué mueran de días Ilenos, que les Iloren su muerte! ¿Qué les cierre un amigo los ojos!

${ }^{28}$ Transcribo y traduzco sólo las primeras estrofas del poema.

Hikma 9 (2010), 55-86 
Malheureux. Ce mot seul déjà vous importune! On craint d'être forcé d'adoucir mes destins! Rassurez-vous, cruels; environné d'alarmes, J'appris à dédaigner vos bienfaits incertains, Et je ne viens ici demander que des larmes.

Savez-vous quel trésor eût satisfait mon cœur? La gloire: mais la gloire est rebelle au malheur, Et le cours de mes maux remonte à ma naissance. Avant que, dégagé des ombres de l'enfance, Je pusse voir l'abîme où j'étais descendu,

Père, mère, fortune, oui, j'avais tout perdu. Du moins l'homme éclairé, prévoyant sa misère,

Enrichit l'avenir de ses travaux présents;

L'enfant croit qu'il vivra comme a vécu son père,

Et tranquille s'endort entre les bras du Temps.

La raison luit enfin, quoique tardive à naître.

Surpris, il se réveille, et chargé de revers,

II se voit sans appui dans un monde pervers, Forcé de haïr l'homme avant de le connaître.

Saison de l'ignorance, ô printemps de mes jours! Faut-il que, tourmenté par un instinct perfide, J'aie, à force de soins, précipité ton cours, Trop lent pour mes désirs, mais déjà si rapide? Ou faut-il qu'aujourd'hui, sans gloire et malheureux, Jusqu'à te désirer je rabaisse mes vœux? Pareil à cet aiglon qui de son nid tranquille, Voyant près du soleil son père transporté Nager avec orgueil dans des flots de clarté, S'élève, bat les airs de son aile indocile, Retombe, et ne pouvant le suivre que des yeux, En accuse son nid, et d'un bec furieux Le disperse brisé, mais en vain le regrette,

Quand, égaré dans l'ombre, il erre sans retraite.

Mais on admire, on aime, on soutient les talents; C'est en vain qu'on voudrait repousser leurs élans: Sur ses pâles rivaux renversant la barrière,

Le génie à grands pas marche dans la carrière. C'est vous qui l'assurez; et moi, que les destins Ont toujours promené sur la scène du monde, Je dis (et ma jeunesse, en naufrages féconde, Étudia longtemps les perfides humains,

Apprit où s'arrêtaient les forces du génie): «Le talent rampe et meurt s'il n'a des ailes d'or, 
"Ou, vendant ses vertus, rare et noble trésor,

«Lève un front couronné de gloire et d'infamie.»

\section{EL POETA DESDICHADO}

Vos a quien se vio siempre mimado por la suerte, ir de éxito en éxito vuestros deseos aireando,

mortal, por un momento, detened vuestros gozos:

Desdichado ;Este término ahora os incomoda, tememos que nos fuercen a endulzar los destinos! Tranquilizaos, crueles; rodeados de alarmas, aprendo a desdeñar vuestro auxilio inseguro, y aquí tan sólo vengo a solicitar lágrimas.

¿Sabéis que tesoro habría encantado a mi alma? La gloria: mas la gloria es reacia a la desdicha y el curso de mis males se remonta a mi origen. Antes que liberado de sombras de la infancia, pudiese ver la fosa a la que había bajado, padre, madre, fortuna, lo había perdido todo. Al menos el sabio hombre, previendo su miseria, su futuro enriquece con trabajos presentes;

cree que vivirá el niño como vivió su padre y tranquilo se duerme en los brazos del Tiempo. La razón por fin brilla, aunque tardía en mostrarse.

Sorprendido derpiértase, y lleno de reveses se ve sin un apoyo en un mundo perverso, forzado de odio el hombre antes de conocerlo.

¡Estación de ignorancia, o esplendor de mis días! ¿Debo yo, atormentado por un instinto pérfido, a fuerza de abandonos precipitar tu curso, muy lento a mis deseos, pero al tiempo tan rápido? ¿O es preciso que hoy, sin gloria y desdichado, hasta ambicionarte yo rebaje mis votos? Igual a este aguilucho que en su nido tranquilo, al ver cerca del sol a su padre extasiado nadando con orgullo en las olas de luz, sube, explora los aires con su alas indómitas, recae, y al poder sólo seguirlo con los ojos, de ello acusa a su nido, y con pico furioso lo dispersa ya roto, mas lo lamenta en vano cuando erra sin retiro extraviado en las sombras.

Mas se admira, se ama, se apoya a los talentos; querríamos en vano rechazar sus impulsos: en sus pálidos émulos la barrera invirtiendo, el genio a zancadas transita en la carrera. 
Vos lo garantizáis; y yo al que los destinos

han conducido siempre a la escena del mundo,

digo (y mi juventud, en naufragios fecundo,

que estudia mucho tiempo a los humanos pérfidos,

aprendió do parábanse los vigores del genio):

"Trepa y muere el talento si no tiene alas de oro,

$o$, al vender sus virtudes, raro y noble tesoro,

levanta un frente ornado de gloria y de infamia».

\subsection{Parny y la melancolía del desencanto ${ }^{29}$}

Ma Retraite

SOLITUDE heureuse et champêtre,

Séjour du repos le plus doux,

Le primeras me ramène à vous;

Recevez enfin votre maître.

La jeune Amante du Zéphir

A ranimé vos tristes plaines;

Echappé de mes lourdes chaînes,

Comme elles, je vais rajeunir

Vous donnez à mes sens une nouvelle vie;

Mon ame trop long-tems flétrie,

Aux rayons naissans du plaisir,

Déjà commence à s'entrouvrir.

$\mathrm{O}$ maîtresse toujours plus chère,

De ces lieux tu fais l'ornement.

Dans ces lieux tu fais sans mystère

Le bonheur du plus tendre Amant.

La simplicité seule orna mon hermitage.

On ne voit point chez moi ces superbes tapis

Que la Perse, à grands frais, teignit pour notre usage.

Je ne repose point sous un dais de rubis;

Mon lit n'est qu'un simple feuillage.

Eh qu'importe! le somme est-il moins consolant?

Les rêves qu'il nous porte eu sont-ils moins aimables?

Le baiser d'une Amante en est-il moins brûlant,

Et les voluptés moins durables?

Pendant la nuit, lorsque je peux

Entendre dégoutter la pluie,

\footnotetext{
${ }^{29}$ Évariste-Désiré de Forges de Parny (1753-1814) es uno de los poetas criollos como Léonard y Bertin, originario como este último de la isla Bourbon. Sus amores contrariados con una criolla de trece años proveerán su obra de materia, publicando en 1778 con gran éxito Poésies érotiques. Poeta que recibiría las alabanzas de sus contemporáneos ("C'est l'éternelle histoire. Parny a eu l'honneur de graver la sienne en quelques vers brûlants, naturels, et que la poésie française n'oubliera jamais" -Sainte-Beuve-; "le seul poète tragique de la France"

Chateaubriand). Su amada Éléonore será un perfecto modelo para la Elvire de Lamartine.
} 
Et les fiers enfans d'Orythie

Ébranler mon toit dans leurs jeux;

Alors si mes bras amoureux

Entourent ma craintive amie,

Puis-je encor former d'autres vœux

Qu'irois-je demander aux Dieux

A qui mon bonheur fait envie!

Je suis au port, \& je me ris

De ces écueils où l'homme échoue.

Je regarde avec un souris

Cette fortune qui se joue

En tourmentant ses favoris ;

Et j'abaisse un œil de mépris

Sur l'inconstance de sa roue.

Gémisse qui voudra sur le sort des humains;

Trop foibles pour être coupables,

Ou trop médians pour être plaints,

Ils ne valent pas les chagrins

Que laisse dans mon cœur l'aspect des misérables.

L'humanité n'est qu'un abus;

La haine est triste \& trop pénible;

Une indifférence paisible

Est la plus sage des vertus.

\section{RETIRO}

Soledad feliz y campestre,

morada del dulce reposo,

la primavera a vos me trae;

recibid al fin a vuestro amo.

La joven amante de Céfiro

reanimó vuestros tristes planes;

huido de mis duras cadenas,

rejuveneceré como ellas,

vos dais a mis sentidos ahora una nueva vida;

mi alma mucho tiempo marchitada,

a los rayos nacientes del placer, comienza ya a entreabrirse.

¡Oh, amante por siempre adorada,

eres de estos lugares el ornato!

En estos sitios haces sin misterio

la dicha del más tierno amante.

La sencillez tan sólo adornó mi retiro.

No se ven en mi casa las soberbias alfombras que Persia ricamente realzó para nuestro uso.

Yo no reposo bajo un dosel de rubies;

mi lecho no es más que un montón de hojarasca.

¡Y qué importa!, ¿el total consuela acaso menos?

Hikma 9 (2010), 55-86 
¿Los sueños que nos trae son menos cariñosos?

¿El beso de una amante es por ello más tibio,

las voluptuosidades son menos perdurables?

De noche, cuando puedo

oír gotear la lluvia

y a los altivos hijos de Oritía

sacudir mi tejado en sus juegos;

jentonces si mis brazos amorosos

rodean a mi temerosa amiga,

podría aún formular otros deseos

que iría a pedirle a los dioses

a quienes mi fortuna da envidia!

Estoy en el puerto y me río

de estos escollos en los que el hombre encalla.

Contemplo con una sonrisa

a esta fortuna que se burla

atormentando a sus validos;

y lanzo una mirada de desprecio

en la inconstancia de su rueda.

Que gima aquel que quiera por la suerte del hombre;

son demasiado débiles para ser los culpables,

o bastante mediocres para compadecerlos,

no valen ni las penas

que dejan en mi pecho el cariz de los pobres.

La humanidad es sólo un error;

el odio es triste y muy penoso;

una indiferencia apacible

de todas las virtudes resulta la más sabia.

\subsection{Legouvé y la melancolía fúnebre ${ }^{30}$}

La MeLANCOLIE $(1800)^{31}$

\footnotetext{
${ }^{30}$ Gabriel-Marie Jean Baptiste Legouvé (1764-1812), de origen parisino es un poeta trágico, descriptivo, traductor de Lucano, su mejor obra es el poema Le Mérite des Femmes, poème. Fue director del Mercure y profesor de poesía latina en el "Collège de France". Maurice Allem nos dice de él en su antología: "Il a composé beaucoup de vers" Anthologie poétique française XVIIle siècle, (1966, p. 488). Sus poemas son en general largos y de temática seria, pudiéndose encontrar en ellos los rasgos característicos de su época como el gusto por lo fúnebre y el culto a la melancolía.

${ }^{31}$ Transcribo y traduzco unos fragmentos de este largo poema de 166 versos, incluido en Le Mérite des femmes et autres poésies par Gabriel Legouvé, Paris, chez Ant. Aug. Renouard, MDCCCXIII, pp.157-166.
} 
La joie a ses plaisirs; mais la Mélancolie, Amante du silence et dans soi recueillie, Dédaigne tous ces jeux, tout ce bruyant bonheur Où s'étourdit l'esprit, où se glace le cœur, L'homme sensible et tendre, à la vive alégresse Préfere la langueur d'une douce tristesse.

II la demande aux arts: suivons-le dans ces lieux Que la peinture orna de ses dons précieux; Il quitte ces tableaux où le pinceau déploie D'une fête, d'un bal la splendeur et la joie, Pour chercher ceux où l'art, attristant sa couleur, D'un amant, d'un proscrit a tracé le malheur. De la toile attendrie, où ces scènes sont peintes, Son ame dans l'extase entend sortir des plaintes, Et son regard avide y demeure attaché...

Sous ces bois inspirants coule-t-il un ruisseau, L'émotion augmente à ce doux bruit de l'eau

Qui, dans son cours plaintif qu'on écoute avec charmes, Semble à la fois rouler des soupirs et des larmes.

Et qu'un saule pleureur, par un penchant heureux, Dans ces flots murmurants trempe ses longs cheveux, Nous ressentons alors dans notre ame amollie Toute la volupté de la mélancolie.

Cette onde gémissante, et ce bel arbre en pleurs, Nous semblent deux amis touchés de nos malheurs; Nous leur disons nos maux, nos souvenirs, nos craintes; Nous croyons leur tristesse attentive à nos plaintes; Et, remplis des regrets qu'ils expriment tous deux, Nous trouvons un bonheur à gémir avec eux...

Ainsi donc le rapport des objets avec nous Leur donne à nos regards un intérêt plus doux! C'est par là que l'automne, heureux soir de l'année, Nous attache au déclin de sa beauté fanée. Lorsque sur les coteaux sifflent les aquilons, Quand la feuille jaunit et tombe en tourbillons, Quand se flétrit des prés la grace fugitive, Le mortel recueilli, d'une vue attentive, Suit cette décadence, où, se couvrant de deuil, La nature à pas lents marche vers le cercueil. Pleure-t-il le trépas d'une épouse adorée, II jouit du tableau de la terre éplorée:

La splendeur du printemps insultoit son ennui; Mais l'automne est souffrant, il se plaît avec lui... 
Où suis-je? à mes regards un humble cimetiere Offre de l'homme éteint la demeure derniere. Un cimetiere aux champs! quel tableau! quel trésor! Là, ne se montrent point l'airain, le marbre, l'or; Là, ne s'élevent point ces tombes fastueuses Où dorment à grands frais les ombres orgueilleuses

De ces usurpateurs par la mort dévorés,

Et jusque dans la mort du peuple séparés.

On y trouve, fermés par des remparts agrestes,

Quelques pierres sans nom, quelques tombes modestes,

Le reste dans la poudre au hasard confondu.

Salut, cendre du pauvre; ah! ce respect t'est dû!

Souvent ceux dont le marbre immense et solitaire

D'un vain poids après eux fatigue encor la terre,

Ne firent que changer de mort dans le tombeau;

Toi, chacun de tes jours fut un bienfait nouveau.

Courbé sur les sillons, de leurs trésors serviles

Ta sueur enrichit l'oisiveté des villes;

Et quand Mars des combats fit retentir le cri,

Tu défendis l'état après l'avoir nourri:

Enfin chaque tombeau de cet enclos tranquille

Renferme un citoyen qui fut toujours utile!

Salut, cendre du pauvre; accepte tous mes pleurs.

Mais quelle autre pensée éveille mes douleurs?

Tel est donc de la mort l'inévitable empire!

Vertueux ou méchant, il faut que l'homme expire.

La foule des humains est un foible troupeau

Qu'effroyable pasteur le Temps mene au tombeau;

Notre sol n'est formé que de poussiere humaine;

Et lorsque dans les champs l'automne nous promene,

Nos pieds inattentifs foulent à chaque pas

Un informe débris, monument du trépas.

Voilà de quels pensers les cercueils m'environnent; Mais, loin que mes esprits à leur aspect s'étonnent,

De l'immortalité je sens mieux le besoin

Quand j'ai pour siège une urne et la mort pour témoin...

Voilà donc tes bienfaits, tendre Mélancolie!

Par toi, de l'univers la scene est embellie;

Tu sais donner un prix aux larmes, aux soupirs;

Et nos afflictions sont presque des plaisirs.

$A h$ ! si l'art à nos yeux veut tracer ton image,

II doit peindre une vierge, assise sous l'ombrage 
Qui, rêveuse, et livrée à des vagues regrets, Nourrit au bruit des flots un chagrin plein d'attraits, Laisse voie en ouvrant ses paupieres timides, Des pleurs voluptueux dans ses regards humides, Et se plâit aux soupirs qui soulevent son sein, Un cyprès devant elle, et Werther à la main.

\section{LA MELANCOLÍA}

Tiene su dicha el júbilo; más la Melancolía, amante del silencio e interiorizada,

desdeña estos recreos, toda esa ardiente dicha en que se aturde el alma y el corazón se hiela; el hombre blando y tierno con la misma alegría la languidez prefiere de una dulce tristeza.

Se la pide a las artes: sigámosle a estos sitios que adornó la pintura con sus preciosos dones; abandona estos cuadros donde el pincel despliega la alegría y esplendor de una fiesta, de un baile, por otros en que el arte, su dolor deplorando, de un amante, un proscrito trazó el infortunio. Del lienzo compungido do estas escenas se pintan, su alma en el éxtasis oye salir las quejas y su mirada ávida allí queda ligada...

Bajo estos 'bosques-musa' transcurre un riachuelo, aumenta la emoción ante el ruido del agua que en su quejoso curso que arrobados oímos, parece que arrastrara lágrimas y suspiros.

Y que un sauce llorón, por un desvío dichoso, en susurrantes olas moja sus largas hojas; percibimos entonces en nuestra alma ablandada la voluptuosidad de la melancolía.

Esta ola quejumbrosa y el bello árbol en lágrimas son como dos amigos que sufren nuestros dramas; les contamos los males, recuerdos y temores; creemos su tristeza atenta a nuestras quejas; $y$, llenos del recuerdo que los dos nos expresan, hallamos una dicha en gemir junto a ellos...

¡Así pues el secreto nuestro con los objetos les da a nuestras miradas un interés más dulce! Por ahí es como el otoño, feliz tarde del año, nos une al ocaso de su belleza ajada. Cuando sobre los cerros soplan los aquilones, amarillea la hoja y cae en torbellinos,

se marchita en los prados la gracia fugitiva, el mortal recogido, con la vista atenta, 
sigue a esta decadencia do al cubrirse de duelo, la natura muy lenta se dirige al féretro.

¿Acaso llora el tránsito de una adorada esposa, o goza con el cuadro de la tierra afligida?: el primaveral brillo insultaba su hastío; pero el sufriente otoño se complace con él...

¿Do estoy?, ante mis ojos un pobre cementerio al hombre extinto ofrece su última morada. ¡Cementerio en el campo!, iqué cuadro!, iqué tesoro! Allí no se reflejan el bronce, mármol, ni oro; allí no se levantan esas tumbas fastuosas donde opulentas duermen las sombras orgullosas de estos usurpadores que devoró la muerte, y hasta en la muerte separados del pueblo.

Cerrados allí se hallan por murallas agrestes, ciertas piedras sin nombre, ciertas tumbas modestas, el resto en el polvo con el azar mezclado. Ceniza del pobre, ihola !; jse te debe respeto! $A$ veces los del mármol inmenso y solitario tras de su peso vano fatigan aún la tierra, tan sólo se cambiaron de muerte en la tumba; para ti, cada día fue una gracia nueva. Encorvado en los surcos de su servil tesoro tu sudor enriquece el ocio de los pueblos; y cuando marzo haga sonar gritos de lucha, tú el estado defiendes tras haberlo nutrido: ¡cada tumba, por último, de esta tranquila cerca esconde a un ciudadano que siempre fue rentable! Ceniza del pobre, ihola!; acepta mis sollozos. Mas, ¿qué pensar distinto despierta mis dolores? ¿Es, pues, el de la muerte, inevitable imperio! Virtuoso o malévolo, el hombre expirar debe. La multitud de humanos es un débil rebaño que el Tiempo, horrible clérigo, conduce a la tumba; nuestro suelo está hecho sólo de polvo humano; y cuando en los campos nos pasea el otoño nuestros pies distraídos lo prensan con sus pasos, un mensaje de restos, monumento del óbito.

Con estos pensamientos me asaltan los ataúdes; mas, lejos de que mi ánimo se asombre ante su aspecto, de la inmortalidad siento su menester si una urna es mi sede y testigo la muerte...

¡Estos son tus favores, dulce melancolía! por ti del universo la escena se embellece; sabes darles un precio a suspiros y lágrimas; 
y nuestras aflicciones casi se hace placeres.

Si el arte a nuestros ojos quiere trazar tu imagen, pintar debe una virgen sentada en el umbrío que ilusa y entregada a vagas pesadumbres, nutra al ruido de olas una pena de encantos, de vía libre al abrir sus párpados medrosos, de voluptuosas lágrimas en sus miradas húmedas y en suspiros complázcase que levanten su seno, un ciprés ante ella y un Werther en la mano.

\title{
2.5. Millevoye (1782-1816) y la melancolía retórica del sufrimiento ${ }^{32}$
}

\author{
LA CHUTE DES FEUILLES ${ }^{33}$ \\ De la dépouille de nos bois \\ L'automne avait jonché la terre; \\ Le bocage était sans mystère, \\ Le rossignol était sans voix. \\ Triste, et mourant à son aurore, \\ Un jeune malade, à pas lents, \\ Parcourait une fois encore \\ Le bois cher à ses premiers ans: \\ "Bois que j'aime, adieu, je succombe. \\ Votre deuil a prédit mon sort, \\ Et dans chaque feuille qui tombe \\ Je lis un présage de mort. \\ Fatal oracle d'Epidaure, \\ Tu m'as dit: Les feuilles des bois \\ A tes yeux jauniront encore, \\ Et c'est pour la dernière fois. \\ La nuit du trépas t'environne; \\ Plus pâle que la pâle automne, \\ Tu t'inclines vers le tombeau. \\ Ta jeunesse sera flétrie \\ Avant l'herbe de la prairie, \\ Avant le pampre du coteau.
}

\footnotetext{
${ }^{32}$ Charles-Hubert Millevoye (1782-1816) fue un niño precoz en poesía que desde muy pronto quiso dedicarse completamente a la escritura, siendo premiados sus versos. Una pasión contrariada lo llevará a caer en la melancolía, donde su temperamento enfermizo iba a encontrar una perfecta plasmación con su destino: la muerte de "langueur" de la joven de quien se había enamorado daría sentido a su vida de poeta. Su obra Amour maternel (1805) representa, junto con Le Mérite des femmes de Legouvé, una etapa de transición entre la Revolución y el Romanticismo incipiente.

${ }^{33}$ Texto de la Anthologie universelle. Choix des meilleures poésies lyriques des diverses nations dans les langues originales par Joaquim Gomez de Souza, Leipzig, F. A. Brockhaus, 1859 , pp. 404-405. El poema obtuvo el premio de la academia de los Juegos Florales de Toulouse, estando considerado como un precedente del "Automne" de Lamartine.
} 
Et je meurs! De sa froide haleine

Un vent funeste m'a touché,

Et mon hiver s'est approché

Quand mon printemps s'écoule à peine.

Arbuste en un seul jour détruit,

Quelques fleurs faisaient ma parure,

Mais ma languissante verdure

Ne laisse après elle aucun fruit.

Tombe, tombe, feuille éphémère!

Voile aux yeux ce triste chemin,

Cache au désespoir de ma mère

La place où je serai demain.

Mais vers la solitaire allée

Si mon amante désolée

Venait pleurer quand le jour fuit,

Éveille par un léger bruit

Mon ombre un instant consolée."

II dit, s'éloigne... et sans retour!

La dernière feuille qui tombe

A signalé son dernier jour.

Sous le chêne on creusa sa tombe.

Mais ce qu'il aimait ne vint pas

Visiter la pierre isolée:

Et le pâtre de la vallée

Troubla seul du bruit de ses pas

Le silence du mausolée.

LA CAÍDA DE LAS HOJAS

Con la broza de nuestros bosques

el otoño había alfombrado la tierra;

el boscaje estaba desnudo

y el ruiseñor permanecía en silencio.

Triste y moribundo en su mañana, un joven enfermo, con paso lento,

recorría otra vez más

el bosque tan querido de sus primeros años:

"Bosque amado, adios, me rindo.

Vuestro duelo predijo ya mi suerte,

y en cada hoja que cae al suelo

leer puedo un presagio de muerte

fatal oráculo de Epidauro,

me dijiste: las hojas de los bosques

a tus ojos aún amarillearán

y será por última vez.

Del tránsito la noche te asalta;

más pálida que el blanquecino otoño,

tú te inclinas hacia la tumba.

Hikma 9 (2010), 55-86 


\section{Tu juventud se agostará}

antes que la hierba de la pradera, antes que el pámpano de la ladera.

¡Y muero! Con su frío aliento

me ha rozado un viento funesto

y mi invierno se ha acercado

cuando mi primavera apenas pasa.

Arbusto destruido en un solo día,

algunas flores formaban mi adorno,

pero su apagado verdor

tras ella fruto alguno deja.

¡Tumba, tumba, hoja efímera!

Oculta a los ojos este triste camino,

esconde a la angustia de mi madre

el lugar donde mañana estaré.

Pero hacia la solitaria alameda,

si mi desconsolada amante

venía a llorar al acabarse el día,

desvelada por un ligero ruido

mi tiniebla un momento consolada."

El habla, jse aleja..., y ya no vuelve!

La última hoja que cae

ha señalado su último día.

Bajo el roble se cavó su tumba.

Mas lo que él amaba no llegó

a visitar la piedra abandonada:

y el clérigo del valle

turbó solo del ruido de sus pasos

el silencio del mausoleo.

\section{CONCLUSIÓN}

Aunque la poesía romántica adquirirá sus cartas de nobleza con Méditations poétiques de Alphonse de Lamartine, ya antes de la publicación de ese libro (1820) toda una atmósfera de desencanto se ha ido gestando en las últimas décadas del siglo anterior. En poesía se llega incluso a revisar, dada su inestabilidad creciente, la noción de "género" en detrimento de la de "estilo"; así, géneros que se basan en su tonalidad (por ejemplo la elegía) van imponiéndose a otros como el soneto o la oda. En cuanto a los estilos, pueden mencionarse cuatro: el "simple", el "gracieux, el "sublime" y el "sombre". Este último adquiere una vigencia de la que no había gozado antes, teniendo en ese hecho una gran importancia la ola creciente en Europa del denominado ossianismo, la influencia de la "Graveyard School" o escuela de los cementerios (con Young y Gray a la cabeza) y el propio clima "moral" de la época, que lleva a algunos escogidos poetas a expresar un rechazo frontal a esa situación de degradación en la sociedad y a refugiarse 
en una poesía más intimista que da rienda suelta a sus anhelos personales. Si durante la primera mitad del siglo imperaba la vivacidad del epigrama (en el que sobresalen autores como Jean-Baptiste Rousseau, Piron, Voltaire y Écouchard-Lebrun ${ }^{34}$ ), el madrigal (Chaulieu, La Faye, Voltaire), la canción (Dufresny, Florian, Fabre d'Églantine), la "poésie légère" o "fugitive" (Voltaire, Sedaine, Marmontel, Delille), la fábula poética (Gresset, Chamfort, Houdar de La Motte, Grécourt, Florian) ya hacia mitad de siglo se va produciendo un ocaso de la poesía clásica en detrimento primero de la poesía didáctica-descriptiva (Saint-Lambert, Delille y Roucher), para que asistamos a la irrupción del prerromanticismo y la poesía melancólica, ya sea con los poetas criollos (Léonard, Bertin, Parny) o con los que se ha dado en denominar "poètes maudits", en el sentido no del "malditismo" como luego preconizará Verlaine, sino de poeta desdichado, infeliz (Malfilâtre, Gilbert), así como otros que se adhieren a la moda del momento y sobresalen en ese tipo de poemas (Thomas, Legouvé, Millevoye...), hasta llegar al poeta más importante del siglo: André Chénier.

REFERENCIAS BIBLIOGRAFICAS

BERCOT, Martine, Michel Collot et Catriona Seth (textes choisis, présentés et annotés par), Anthologie de la poésie française $X V I I I^{e}$ siècle, $X I X^{e}$ siècle, $X X^{e}$ siècle, Paris, Gallimard, 2000.

BRESSY, Joseph, Recherches sur les vapeurs, Paris-London, Planche, 1789.

BURTON, Robert, The Anatomy of Melancholy, What it is: With all the Kinds, Causes, Symptomes, Prognostickes, and Several Cures of it. In Three Maine Partitions with their several Sections, Members, and Subsections. Philosophically, Medicinally, Historically, Opened and Cut Up, ed. Jackson Holbrook London, Dent, 1932.

CAmUS, Albert, "Introduction aux Maximes de Chamfort", in Essais critiques, Essais, Paris, Gallimard, 1965, pp. 1099-1109.

CHAMFORT, "L'heureux temps", in CEuvres de Chamfort, précédées d'une étude sur sa vie et sur son esprit par Arsène Houssaye, Paris, Adolphe Delahays, 1857, pp. 324-235.

DAVID, Sylvain, "De l'inconvénient d'être pauvre: discours de l'indigence et indigence du discours", in Imaginaire social et discours économique, sous la direction de Mauricio Segura et alii, Montréal, Université de Montréal, Département d'études françaises, coll. "Paragraphes», 2003, pp. 61-72.

DIAZ, José Luis, "Le 'Poète-misère'. La mort en prose de l'écrivain sous la monarchie de Juillet", in Les imaginaires de l'écriture. Personnages et

${ }^{34}$ Se han publicado seis libros de sus epigramas, conteniendo 636; en su tiempo conoció un éxito inmenso y fue bautizado con el pomposo nombre de Lebrun-Pindare, aunque luego muriera en la miseria. 
scénarios de la vie littéraire, sous la direction de Pascal Brissette et Maxime Prévost, Québec, Nota Bene, 2006, pp. 37-58.

FELS, Laurent, "Millevoye: Élégies", in In-fusion: revue littéraire, ํ1, Asnières-sur-Seine, 2008, pp. 19-36.

FESTA-MCCORMICK, Diana, "The Myth of the Poètes Maudits", in Pretext/Text/ Context: Essays on Nineteenth-Century French Literature, sous la direction de Robert L. Mitchell, Colombus, Ohio State University Press, 1980, pp. 199-215,

Garcia PeinAdo, M. Á., "La influencia en Francia de la poesía sepulcral inglesa del XVIII: Les Tombeaux (Aimé Feutry), Les Tombeaux champêtres (Chateaubriand), Les Sépultures (Lamartine), Hermeneus, ํㅜ 7, 2005.

GILBERT, Nicolas-Joseph-Laurent, CEuvres, précédées d'une notice historique par Charles Nodier, Paris, Urbain Canel 1833.

KRISTEVA, Julia, "Les abîmes de l'âme", Magazine littéraire, № 244, juilletaoût, 1987, pp. 16-18.

—, Soleil noir, dépression et mélancolie, Paris, Gallimard, 1987.

LAROUSSE, Pierre, Grand dictionnaire universel du XIX siècle: français, historique, géographique, mythologique, bibliographique..., 17 vols. Paris, 1866-1877 (réimp.: Nimes, 1990).

Millevoye, Charles-Hubert, CEuvres de Millevoye, 3 vols., éd. par Paul Lacroix, Paris, Quantin, 1880.

Seth, Catriona, Les Poètes créoles du XVIII siècle, Roma-Paris, Memini, 1998.

Stavan, H. A., "La Nostalgie et la Mélancolie dans les Saisons de Leonard", C.R.A.C., $\mathrm{n}^{\circ}$ 6, 1986.

STEINMETZ, Jean-Luc, "Du poète malheureux au poète maudit (réflexions sur la constitution du mythe)", Signets, Paris, Corti, 1995.

WoJCIECHOWKa BIANCO, B., Gillbert, Poeta del "Malheur", Lecce, Adriatica editrice salentina, 1984. 